\title{
AC 2009-1349: A STRUCTURED APPROACH TO INNOVATION: A CLASSROOM EXPERIENCE IN INVENTIVE PROBLEM SOLVING FOR AN ENTREPRENEURIAL PROGRAM
}

\section{Dana Clarke, Applied Innovation Alliance}

Dana W. Clarke, Sr. is President/CEO of Applied Innovation Alliance, LLC. Mr. Clarke has over 30 years of industry experience in solving the most difficult problems business, science and engineering. Prior to this, he spend 18 years with Emerson Electric Corp. where he was involved in product and process development, 5 years working with many of the leading TRIZ experts in the US as their customer and 5 years as an employee of Ideation International. Having become involved in TRIZ in late 1991, He became the first American to become certified as a TRIZ Specialist by a TRIZ Master in 1995 and the first to become internationally recognized as a TRIZ Specialist by the International Association of TRIZ (2001). Leveraging his knowledge of business, engineering and innovation Dana is the founder and President/CEO of Clarke Ventures, LLC (an investment and holding company), CNVGenes, LLC and Fluid Insights, LLC. CNVGenes is involved in the development of methods and devices for counting copy number variation (CNV) of genes and DNA-DNA hybridization. Fluid Insights is involved in the development of a new generation of devices for near micro-dosing and processing of fluids. His expertise encompasses the practical application, consulting, facilitation and training of such methodologies and business practices as TRIZ, Competitive Opportunity Management, Strategic Planning, Competitive Intelligence, Product / Process Development and Optimization, Business Process Innovation, Design for Manufacture and Assembly, Quality Function Deployment, Technology Research and Organizational Engineering.

\section{Donald Reimer, Lawrence Technological University}

Donald M. Reimer is currently a fulltime senior lecturer and Associate Director of The Lear Entrepreneurial Program in College of Engineering at Lawrence Tech. Mr. Reimer holds a Bachelor of Science degree in Industrial Management from Lawrence Technological University and a Master of Arts degree in Political Science from University of Detroit/Mercy. He is a Certified Management Consultant with over 35 years of experience in working with closely-held businesses. Mr. Reimer has served as an adjunct faculty member at Lawrence Technological University for over twenty-years. He has taught courses in entrepreneurship, management and corporate entrepreneurship and innovation for engineers. Mr. Reimer has operated his own consulting company - The Small Business Strategy Group for 23 years. He published numerous articles on small business, entrepreneurship and strategic thinking. Mr. Reimer conducted workshops and seminars for trade associations, chamber of commerce organizations and private companies. He has received several awards and recognition by local, state and federal agencies for his work in entrepreneurship and minority business development. Mr. Reimer served as member of the Minority Economic Development Committee of New Detroit. Mr. Reimer is member of the Small Business Advisory Council of the Detroit Regional Chamber of Commerce. Mr. Reimer is a member of Advisory Board of the Milwaukee Junction Small Business Assistance Center. He is also a member of the Applied Innovation Alliance. Mr. Reimer serves as a KEEN Fellow for The Kern Family Foundation and is a member of United States Association of Small Business and Entrepreneurship.

\section{Ahad Ali, Lawrence Technological University}

Ahad Ali is an Assistant Professor in Mechanical Engineering at the Lawrence Tech University. He earned B.S. in Mechanical Engineering from Bangladesh Institute of Technology, Khulna, Masters in Systems and Engineering Management from Nanyang Technological University, Singapore and PhD in Industrial Engineering from University of Wisconsin-Milwaukee. Dr. Ali was Assistant Professor in Industrial Engineering at the University of Puerto Rico - Mayaguez, Visiting Assistant Professor in Mechanical, Industrial and Manufacturing Engineering at the University of Toledo, and Lecturer in Mechanical Engineering at the Bangladesh Institute of 
Technology, Khulna. He has published journal and conference papers. Dr Ali has done research projects with Delphi Automotive System, GE Medical Systems, Harley-Davidson Motor Company, International Truck and Engine Corporation (ITEC), National/Panasonic Electronics, and Rockwell Automation. His research interests include manufacturing systems modeling, simulation and optimization, intelligent scheduling and planning, artificial intelligence, predictive maintenance, e-manufacturing, and lean manufacturing. He is member of IIE, INFORMS, SME and IEEE. 


\title{
A Structured Approach to Innovation - A Classroom Experience in Inventive Problem Solving for Entrepreneurial Program
}

\begin{abstract}
This paper describes a unique course on Structured Approaches to Innovation for Lear Entrepreneurial Program in College of Engineering at the Lawrence Technological University. Lawrence Tech's Lear Entrepreneurial Program offers the opportunity to work in a businessmodel setting to solve real-world engineering problems. Students in any of Lawrence Tech's undergraduate engineering disciplines have the unique option to bring real products and services to market, while solving real-world engineering problems. Students prepare to run their own companies, be an integral part of a small company or lead successful projects in a larger company.
\end{abstract}

This course is designed to deliver Structured Innovation skills and knowledge that enhanced the problem solving capabilities of students in entrepreneurial or entrepreneurial environments. When approaching an engineering problem, it gives a structured and very visual way to attack a problem. Team based learning environment was used. Two student groups were created. One team had four students and other five representing civil, mechanical and electrical engineering disciplines. Each team developed a Team Charter in which the problem was defined. Each was challenged to solve the same problem applying the tools and methods learned in the class lectures and reading materials. Each team was to evaluate the Apple IPOD for possible hearing loss to users due to the design of the earphones. Each team was given the charge of modifying or redesigning the earphones to reduce the potential of hearing loss. Students were asked to apply structured approaches including unique theoretical concepts, unique conceptual tools and unique analytical tools (e.g. four-step process, ideal thinking, resources analysis, resolving contradictions, separation principles, evolutionary patterns, etc.). Each team presented one or more possible solutions to the problem at the conclusion of the class. Student learning experiences were a key issue how to use an innovation process to better organize thoughts and hopefully create more innovative solutions. Structured Innovation allows looking at the problem in a new way.

\section{Course Development - Structured Approaches to Innovation}

The challenge of understanding innovation as a structured process is addressed in the Structured Approaches to Innovation course. It was developed within the College of Engineering at the Lawrence Technological University. Lawrence Tech is a private university founded in 1932. It has approximately 4,100 students and is located in Southfield, Michigan. The college offers undergraduate, graduate and doctorial degrees in architecture and design, management, arts and sciences and engineering. It has a strong commitment to development students with an entrepreneurial mindset with a global view.

The development of this course was made possible by a grant from The Kern Family Foundation. Lawrence Tech is one of twenty two colleges and universities that are part of the Kern 
Entrepreneurial Education Network (KEEN). This network focuses on developing an entrepreneurial mindset among engineering students.

Innovative thinking is a key ingredient of business, technology, government, healthcare and any other endeavor spanning solving problems to the development of strategies and making decisions in the boardroom. An awareness and understanding of systems thinking and the use of a structured approach to innovation was the foundation for development of a pilot course within the Lear Entrepreneurial Program at Lawrence Tech. The course was introduced in spring 2007 with nine students participating in the pilot phase. The students included from civil, mechanical and electrical engineering programs.

\section{Course Objectives}

The course, Structured Approaches to Innovation was offered as an elective for junior and seniors within the Lear Entrepreneurial Program of the College of Engineering. The course was delivered in a conventional, self-contained classroom format, expanded to include hand-on work in a team environment. The intent of the course was to deliver Structured Innovation skills and knowledge that enhanced the problem solving capabilities of the students in entrepreneurial or intrapreneurial environments.

\section{Selected Articles and Experience}

The instructors utilized personal experiences, cases, articles and class discussions. Students were expected to participate in the learning process by bringing personal experiences and reflecting on the articles, cases and class discussions on Business Week articles, HBR articles including Peter F. Drucker's article and TRIZ Journal to research specific topics; ideality, resources, etc.

\section{Speakers}

The instructors arranged to bring in three speakers (one from industry, one with extensive experience in Structured Innovation and a recent graduate who is employed as an innovation technologist) to address Structured Innovation, cross functional teams, innovative thinking and the organizational cultures for innovation. Students' feedback on each speaker presentation was a part of their assignments.

\section{Problem Statement and Team Charter}

Two student groups were created. One team had four students and other five. The teams were asked to prepare a Team Charter that clearly defined the problem and their approach to solving the problem. Each was given the same problem to solve. Each team was directed to solve the problem by applying the tools and methods learned in class.

\section{Problem Statement}

Students were asked to evaluate the Apple product known as an IPOD for possible loss of hearing due to design of the earphones. Each team was given the responsibility of modifying or 
redesigning the ear phones to reduce the potential loss of hearing. Each team is used the structured approach including the Four Step Process and the application of the 40 Principles.

\section{Learning and Solving - An Experiential Process}

To solve the problem, the students attacked the IPOD using Structured Innovation to identify a variety of ways to resolve the possible hearing loss problem. Their work was based on the sued of a structured methodology that included the foundational elements of Structured Innovation including a simple four step process, ideality, resources, contradictions, separation principles, secondary problems, systems approach thinking, 40 principles and evolutionary patterns.

\section{Possible Solutions}

Each team developed a solution the four step process and a systems thinking approach to reach a possible solution to the problem. This assignment was an integral part of the experiential learning component of the course. Each team must present their possible solutions at the end of the class. Many solutions were developed and presented. All recommendations were based on applying the tools and methods learned. All solutions presented included modifying the design as well as a complete redesign of the earphone system.

\section{Lessons Learned}

The students presented their recommendations utilizing the language of innovation they learned in class. Reference to the terminology and the application of the four steps process was clearly evident in the presentations. An awareness of ideality, resource utilization, secondary problems, contradictions, separation principles and the 40 principles provided evidence that a "system thinking" approach had been utilized in addressing the problem and its solution.

As educators, our interest focused on the application of the "system thinking" in developing solutions to real problems. Students learned to think differently and apply what was learned? They learned more about the "systems thinking" methodology and tools. The validation of the lessons learned was evident at a display of senior projects at LTU open house event at the end of the course. One of student said, "If I only understood the concept of "separation principles" prior to senior projects, I would make a change in the design of this product." This statement goes to the heart of what this pilot was also about - changing how our students approach solving problems.

\section{Foundational Elements - Body of Knowledge}

\section{Innovation}

Innovation has been and will continue to be a critical part of mankind's existence. Having existed since the being, extremely high-level innovation talent was historically delivered by an easily identified small percentage of the population; daVinci, Whitney, Franklin, Bell, Edison, etc. But that was yesterday, when how to innovate could not be easily articulated, was not structured and therefore not taught, it occurred randomly and was unmanaged. Yet mankind 
flourished over the millennia. Today, we have the ability to and are accelerating how innovation occurs. We now understand how people have solved problems and what the thought processes of the most talented innovators are. We have the ability to bring "innovation talent" to business, engineering and scientific talent thereby accelerating how innovation occurs. Innovation can be structured, teachable, repeated at will, manageable, easily communicated, delivered by both individuals and teams and applicable to area of business, government, healthcare, etc.

Bringing structure to innovation provides a bridge between right- and left-brain functions. Research has shown that historically the education system systematically drove creativity and innovativeness out of children at an early age. As this occurred within education systems, educators were also shaping lives by gradually increasing the structure and discipline maturing adolescents needed. Beyond these inherent needs for structure and discipline lie the curriculum of language, mathematics, science, history, culture, etc. all of which are critical to the development of successful careers and the development of entrepreneurs. This constant transition toward the development of our minds gradually moves a large percentage of the population toward left-brain analytical thinking. Yet the demand for creativity and innovativeness has tended to be thought of as right-brain functions. Bringing structure to innovation blends rightand left-brain functions.

Normally innovation is not as structured as mathematics. However, nowadays Structured Innovation is about $60-70 \%$ people and $30-40 \%$ methods, tools and techniques. It is also being integrated with mathematics, delivering results at an accelerated pace and facilitating the resolution of problems that have be perceived as impossible to solve. Therefore, innovation could be structured in some forms. With over 60 definitions available via the Internet, the definition of innovation is somewhat illusive but foundationally it has been defined as "the creation of something new that delivers value to our customers and to our organizations." This definition only tells us "what" innovation is and not "how to deliver" innovation which is critical to the development of "innovation talent" through the transfer of knowledge. There is also the need to move beyond individual innovation talent to the development of highly innovative teams. Business, engineering or scientific talent is NOT the same as innovation talent.

\section{Transition from TRIZ}

It is easy for one to say that once something new, such as, TRIZ is created that this great discovery is the end and we now know all we will every need to know but, the reality is that this is never true. One only needs to look at math, written language, quality or any innovation/invention to understand that all systems of value continue to evolve and that they typically start out as crude representations of what eventually evolves. For example, we are not using Roman numerals, we are not stuck with the first written language of cuneiform based on symbolic forms, of quality of 70 years ago based on the sorting of parts or the first invention of an internal combustion engine in the 1600's based on the use of gunpowder. All systems of value evolve and TRIZ is no different and it is important for both academics and professionals to commit to improving on the foundation work of Genrich Altshuller.

In 1946, a Russian Navy Patent Office agent, Genrich Altshuller, realized that there was information hidden inside patents (and the history of technology) and sought to extract that 
knowledge. Over the next 40 years, he developed a theoretical foundation for TRIZ, The Theory of Inventive Problem Solving. Altshuller's seminal work initiated a paradigm shift that is yet to be fully appreciated. This paradigm shift is at least as significant as the development of mathematics and quite possibly as important as the development of communications. The primary difference between TRIZ and mathematics and communications is that they have hundreds to thousands of years, respectively, of a head start.

The development of the TRIZ (invention-based) theoretical foundation provided us with many interesting concepts and principles having their roots patents and the chemical and mechanical engineering focus of Altshuller. In addition to this it was technologically limited by its growth and application in a communist country that was void of entrepreneurship, customer focus, market dynamics, competition and other Western business characteristics $[1,2]$. The Transition from yesterday to today has spanned the last 60 years and included:

- Research of innovation

- History of technology - TRIZ

- Worldwide patents - TRIZ

- Expanded research of innovation

- Psychological processes of inventing - minimally TRIZ-base

- Evolution of business - beyond TRIZ

- Evolution of markets and market dynamics - beyond TRIZ

This past and continuing research has led to the development of methods, tools and techniques:

- Structuring the processes of innovating and inventing - strongly TRIZ-based

- $\quad$ Structuring the process of predicting and preventing failures - partially TRIZ-based

- Mapping the future evolution of business opportunities and technological systems minimally TRIZ-based

- Developing innovation as a core competency - beyond TRIZ

Tomorrow structured approaches to innovation will be a disciplined business talent that is pervasive; it is no different than the pervasiveness of mathematics and communications. And like today's levels of advance mathematics, written language, quality methods and innovations like the internal combustion engine, innovation will continue to evolve. As innovation is touched by academics, researchers, professionals and students it will continue to change. At the same time the foundational elements will remain, e.g., Roman numerals that brought us addition and subtraction, symbolic writing is a foundational element of computer interfaces, the sorting of parts through measurement is a part of all manufacturing processes and the foundational elements of internal combustions engines are all still a part of our lives.

With the transition of TRIZ outside the Soviet Union, the foundational elements of TRIZ have evolved to including competitive and business intelligence, strategic planning, the evolution of markets and market demand, team influences and the structuring/restructuring of knowledge with the intent of:

- Generating one-time cash flow benefits

- Saving product development cost

- Improving on-going operational costs

- Increasing existing market profit 
- Increasing existing market share

- Taking control of a new market niche

- Increasing overall market size

- Creating whole new markets

- Increasing P/E multiple for the enterprise

At General Dynamics Land Systems, two Structured Innovation methods have been utilized; Competitive Opportunity Management (COM) and Innovation RainMakers®. COM brings new approaches to company business models and strategic processes and use used to develop novel strategies for internal $\mathrm{R} \& \mathrm{D}$, software/hardware integration and product definition baselines. Innovation RainMakers ${ }^{\circledR}$ that solves tactical problems and exposes a wider group to innovation tools. COM was also used to develop a company power and energy roadmap. Innovation RainMakers ${ }^{\circledR}$ allows instant application of Structured Innovation techniques, supported by an innovation expert, to solve technical problems quickly and efficiently. Innovation RainMakers® projects have yielded advancements in product reliability, weight reduction, ceramic armor and electromagnetic interference filters [3].

Transitioning away from being a "theory" and the limitation of "inventive problem solving", Structured Innovation's definition provides a basis for how we have advanced TRIZ and will continue to evolve Structured Innovation as well as how we work to solve challenging problems.

This definition covers several key differences (Figure 1):

1) It defines how innovation occurs.

2) It is about methods, tools and techniques and people.

3) It suggests that people carry the knowledge required to solve problems.

4) It is about the structuring and restructuring of knowledge.

5) It is about the delivery of quantifiable results because without results innovation never really occurs.

For Structured Innovation to exist the following are required:

- Existence and use of a common language for innovation

- Utilization of processes and tools

- Applicable by both individuals and teams

- Applicable to all areas of business

- Enablement of new levels of decision making

- Delivery of measurable progress and results

Structured Innovation: the science of innovation

- Foundation - Research of patent, history of technology, business, markets, psychology, etc.

- Language - Ideality, resources, resource profiling, contradiction, secondary problems, etc.

- Methods - 4-step process for solving inventive level problems, more involved algorithms for invention, failure analysis, failure prediction, risk assessment, patent analysis, competitive opportunity management, etc.

- Principles - Over 850 inventive and evolutionary for all walks of life including science, engineering, business, education, government, personal, etc. 
All of which are based on well-defined:

- Unique theoretical concepts

- Unique conceptual tools

- Unique analytical tools

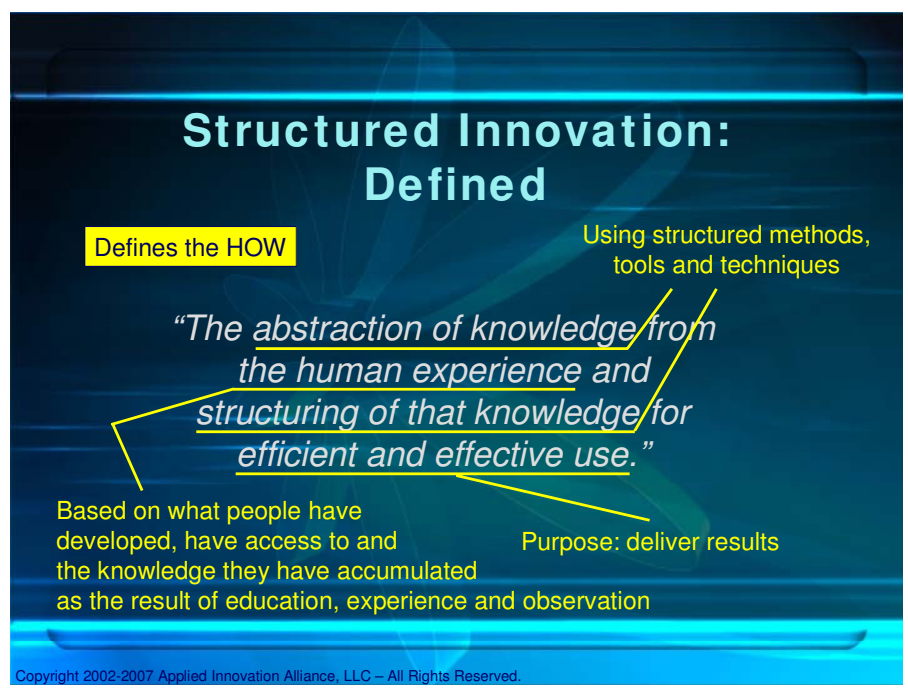

Figure 1: Structured Innovation Definition

A basic requirement of all Structured Innovation methods, tools and techniques is that it can be applied to all areas of life, business and business development, e.g., business, government, homeland security, defense, healthcare, medical, construction, architecture, education (psychology, sociology, science, engineering, history, etc.), life sciences, alternative energy, advanced automotive, electronics, entrepreneurial initiatives, information technology, business creation, and more.

\section{Underlying Pedagogy}

The pedagogy used to deliver the material in the class was designed to be interactive. The syllabus, course schedule and assignments were available to the students on Blackboard. Since the class was taught by two instructors, it provides an opportunity for interaction and numerous real world experiences.

This course is foundational to creating an awareness and basic understanding of the nature and language of innovation. Therefore, an effective pedagogy must be utilized in the learning process. As instructors, both of us realized that the challenge was one of changing the way people think. Fortunately, the students had a positive attitude, an open mind and a strong commitment to learn.

Incorporated in the pedagogy was experiential learning which focus on changing the way students think. Each student was directly involved in solving a real world problem. The methods and tool learned in class were immediately transferred into practice. The theory of the science of 
innovation was communicated through illustration and demonstration in the resolution of real world problems.

The use of outside speakers from industry provides another strong link between theory and practice. The speakers provided examples of how the Structured Innovation process has been utilized to solve tough problems.

\section{Body of Knowledge}

Structured Innovation, like other sciences, has a "Body of Knowledge" that is key to understanding the science. Therefore, we focused on teaching the "Body of Knowledge" and its application to solving real world problems. This course is the first step in the journey of learning the language of innovation. The best way to learn is by doing. This is why experiential learning is so important. The following describes the foundational elements and/or components of Structured Innovation that were taught in the pilot course:

\section{Methods, Tools, and Techniques}

Figure 2 presents the process and principles utilize with the students to develop basic innovation skills.

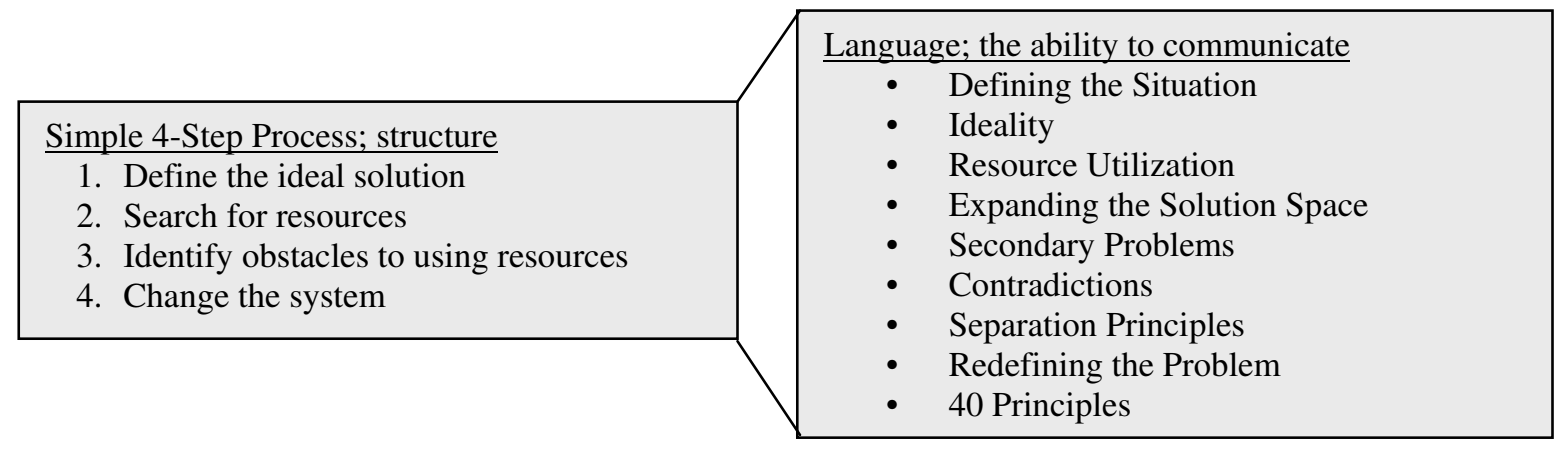

Figure 2: Simple 4-Step Process Structure

\section{Selected Examples}

\section{Four-Step Process}

The following four steps provide a simple, easy to remember process for solving inventive-level problems (Figure 3). To support this process the students were taught how to use the process in a timeframe of minutes as well as being taught a collection of tools used within the process. Note: The assumption is that a problem has been defined prior to this process being initiated.

1. Define the ideal solution

2. Search for resources

3. Identify obstacles to using resources

4. Change the system 


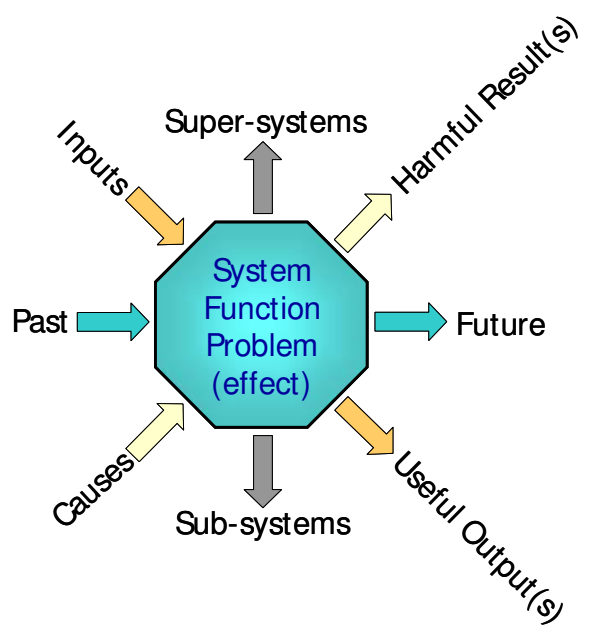

Figure 3: System Function for 4-Step Process

\section{Systems Approach Model}

The students were taught that while defining the problem appears to be easy, a simple model can be used to clearly articulate the problem in the context of time, system hierarchy, cause / effect / harmful results, and inputs / output results and that all of this can easily be done in the confines of a short meeting allowing the problem solving process to be initiated very quickly.

In many problem solving approaches, the first two steps look like this:

- Define the Problem.

- Identify the Cause of the Problem.

It is as if the problem exists with no context-no surrounding function or system. Using Structured Innovation to solve a problem involves seeing the problem as part of a system. Accurately defining the problem within its surrounding system can lead to more efficient and effective problem solving.

The students learned that each of the four axes provides the opportunity to more fully understand the situation they are faced with. By logically working the model, starting with the problem definition, defining the function that is negatively impacted by the problem and then the system they learned to clearly set the stage for problem solving. There is more to the Systems Thinking than responding to the questions presented thus far. The following System Approach Thinking Model serves multiple purposes:

- Questioning to define the situation

- Expand the solution space

- Redefine the problem 


\section{Ideality}

The "ideal" occurs when a useful function is performed without any harmful effect (such as cost, quality problems, complexity, or waste). Even though this may be impossible to achieve, striving for "Ideality" positions us for success. By approaching problems from a view point of Ideality the students learn how to reduce psychological inertia and therefore have a much greater opportunity to discover a new set of solutions and potentially find a more ideal solution.

\section{Resources}

Achieving ideal or nearly ideal solutions is significantly enhanced when innovators understand the concept of resources (Figure 4). The students developed an understanding of resources and how to see inside systems to find what they need to solve a problem. They learned that being able to find, create or modify resources allowed them to solve problems without having to purchase the solution.

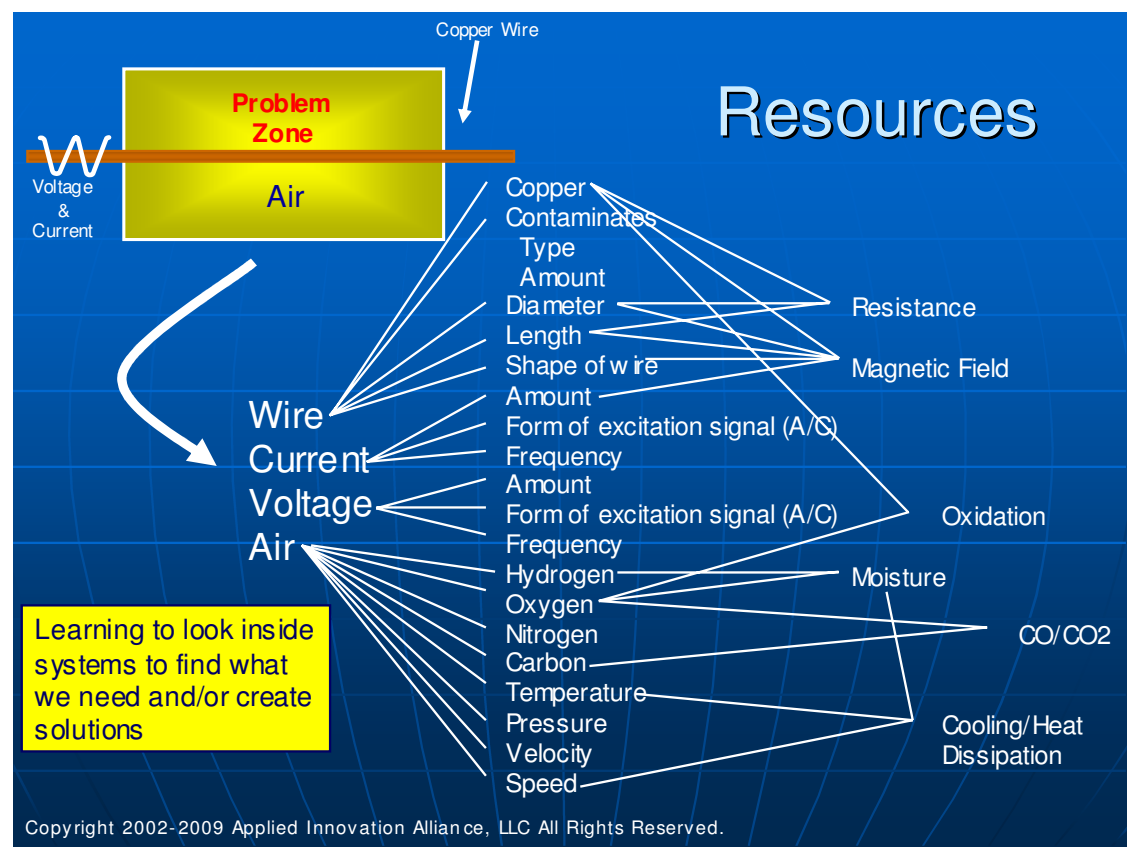

Figure 4: Concept of Resources

\section{Secondary Problems}

Understanding how to deal with secondary problems is a key differentiator between brainstorming and structured approaches to innovation. The students learned that every idea has a new problem associated with it and that the objective is to immediately identify and apply the four-step process to try to solve the new problem. The tougher the challenge the more critical it is to aggressively pursue solving secondary problems. 


\section{Contradictions and Separation Principles}

One of Genrich Altshuller's [4] key research-based discoveries was that the common thread between all great innovations, inventive problems, (except accidental discoveries) was that they are the result of resolving contradictions (contradictory requirements) which is shown in Figure 5. The students learned the difference between complex (aka physical) contradictions and simple (aka technical) contradictions and how to convert from complex to simple as well as how to utilize separation principles to resolve contradictions.

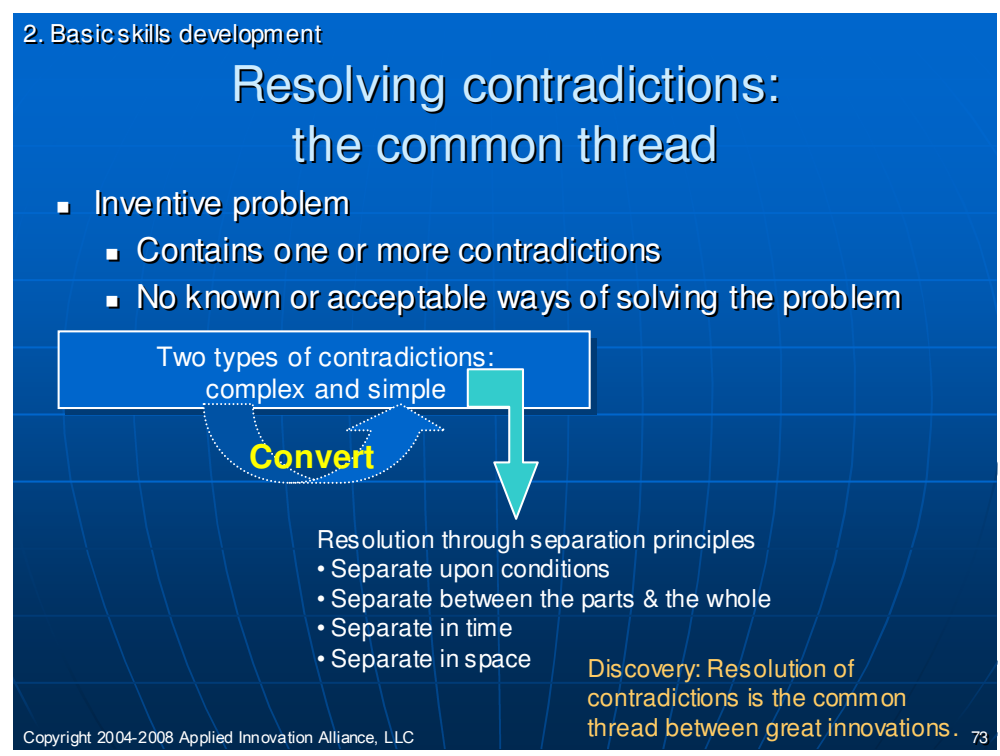

Figure 5: Resolving Contradictions

\section{Principles}

A common set of TRIZ tools were taught in the context of solving technical problems and in the context of solving business problems. These important principles, another research-based discovery of Altshuller, provide a great means solving contradictory requirements, drawing analogies and identifying new ways to attach challenging problems.

\section{Evolutionary Patterns}

Systems do not evolve randomly; they evolve according to objective patterns (Figure 6). By learning this, the students we taught how to purposefully evolve business and technological system to the next generation with reduced trial and error attempts.

\section{Lawrence Tech University's Structured Innovation Pilot Course}

The LTU course is foundationally based on the basic innovation skills found in TRIZ with several distinct modifications such as:

- Experiential learning

- Team focused problem solving 
- Minor modifications in the language and the way the methods, tools and techniques are communicated

- Elimination of antiquated approaches found in traditional TRIZ materials

- Inclusion of linkages to mathematics

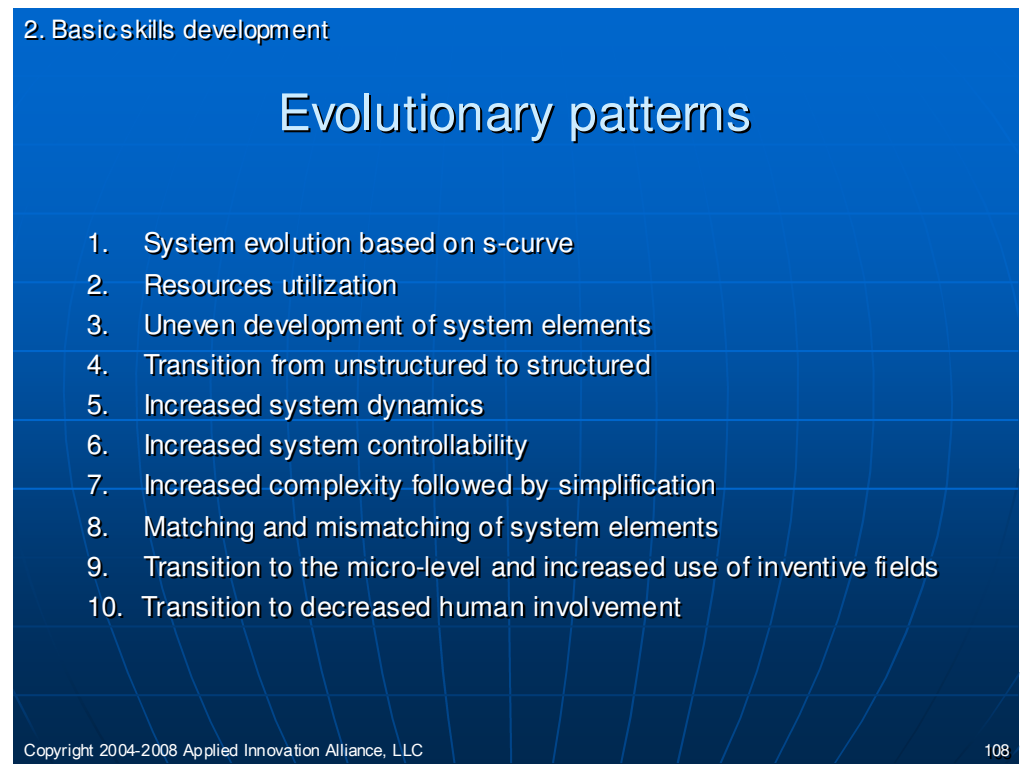

Figure 6: Evolutionary Patterns

Potential expansion beyond the pilot course could include:

- Advanced approaches to inventive problem solving for engineering and science disciplines

- Advanced approaches to inventive problem solving for business disciplines

- Inventive approaches to failure analysis and elimination

- Inventive approaches to risk profiling and mitigation

- Evolutionary development of business and technological systems

- Analysis of competitive environments and market demand

- Analysis of patent claims for patent deconstruction / reconstruction

- Development of foundational maps for the development of nurseries of patents

- Strategically evolving the future of business and technological systems

The above applications are examples of direct application, modification and the integration of TRIZ band for attacking various business needs.

Following comments from the students of pilot course show how structural innovation helped them in learning.

"After learning the methods and tools from Structured Innovation, I believe it will change the way I approach any problem. When approaching an engineering problem, it gives a structured and very visual way to attack a problem. I am a very visual learner and thinker therefore I am more likely to use these methods since they use my strengths. I have learned to be more positive in my thinking and follow through with ideas." Pilot Course Graduate 
"Learning about Structured Innovation impacts my everyday thinking. In order to solve many problems that I face in and outside of class, I can see myself looking at the system as a whole and the resources that can be used to utilize different adaptations or changes to evolve the system closer to ideality." Pilot Course Graduate

"Using structure innovation gives me a place to start instead of depending on random brainstorming. With it I can use the 4-step process or the 40 principles to solve issues that would have taken weeks of unproductive brainstorming. Whether with a group or individual, it will make problem solving a much easier task than it was before." Pilot Course Graduate

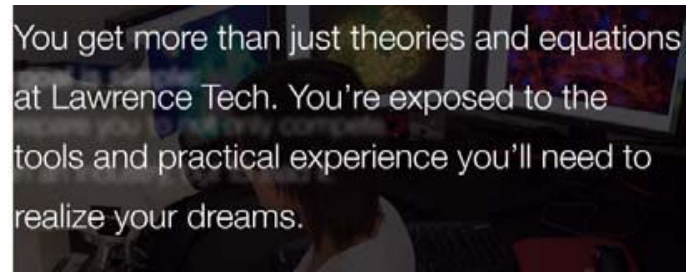

"Learning about Structured Innovation impacts my everyday thinking. In order to solve many problems that I face in and outside of class, I can see myself looking at the system as a whole and the resources that can be used to utilize different adaptations or changes to evolve the system closer to ideality." Pilot Course Graduate

\section{Differences between TRIZ and Structured Innovation}

At an entry-level TRIZ and Structure Innovation appear to be similar with only subtle differences. At this level, the primary differences are minor adjustments in language, the use of improved methods and the way teams are facilitated and developed [1,2]. Table 1 shows the differences between TRIZ and Structured Innovation.

\section{Linking Structured Innovation to Education}

Innovation is basic to all walks of life and has always been integral to mankind's evolution. It has also been an integral part of all aspects of education but to date innovation has lacked structure and structured integration within the education system and course offerings. Because innovation is "way of thinking", it is as basic as communications; at some level people are innovating day-in and day-out. Structured approaches to innovation can be used to improve the education system, can be taught as a course and more importantly can be integrated with course so it becomes as integrated as communications and mathematics. Few examples beyond establishing a sequence of courses are presented in the followings.

- Integrate basic innovation skills within existing courses

○ Link "resource profiling" into mathematics and science, a case study example

- Problem: Mathematical models and resulting simulations for modeling the rapid release have high levels of electrical energy in close proximity to electrical systems were insufficient - leading academics and industry experts had been engaged for over 2 years to no avail.

- Solution: "Resource profiling", a process designed to inventively identify and combine science-based resources to achieve a specific objective. 
Table 1: Differences between TRIZ and Structured Innovation

\begin{tabular}{|c|c|}
\hline TRIZ & Structured Innovation \\
\hline $\begin{array}{l}\text { The Theory of Inventive Problem } \\
\text { Solving - focused on inventing. }\end{array}$ & $\begin{array}{l}\text { The abstraction of knowledge from the human experience and } \\
\text { structuring of that knowledge for efficient and effective use. Note: } \\
\text { This definition define what and how Structured Innovation does as } \\
\text { well as how we expand Structured Innovation methods, tools and } \\
\text { techniques to reinvent our work. Structured Innovation is focused on } \\
\text { the practical application and delivery of results; it is not a theory; at } \\
\text { an entry-level, it includes the ability to solve inventive-level problem } \\
\text { but this is not its primary focus; it is primarily a team-based process } \\
\text { that respects and leverages the knowledge of expert teams. At a more } \\
\text { advanced level, Structured Innovation is used to develop high level } \\
\text { strategy development and strategically evolving the future. }\end{array}$ \\
\hline $\begin{array}{l}\text { Foundation material based on science } \\
\text { and engineering - based on the research } \\
\text { of patents / history of technology. }\end{array}$ & $\begin{array}{l}\text { Foundation TRIZ, Competitive / Business Intelligence, Strategic } \\
\text { Planning, Market Evolution and Market Dynamics, Product / } \\
\text { Portfolio Planning and Development and Change Management - } \\
\text { designed to span all areas and levels of business, government, } \\
\text { healthcare, etc. }\end{array}$ \\
\hline $\begin{array}{l}\text { Collection of methods, tools and } \\
\text { techniques developed by Genrich } \\
\text { Altshuller between } 1946 \text { and } 1985 .\end{array}$ & $\begin{array}{l}\text { Collection of unique theoretical concepts, unique conceptual tools and } \\
\text { unique analytical tools designed to solve problems in all walks of life. } \\
\text { Includes integrated methods, tools and techniques developed by Dana } \\
\text { W. Clarke, Sr. between } 1991 \text { to present based on the research and } \\
\text { development, restructuring and integration of TRIZ with the best-of- } \\
\text { the best business practices; includes early stage integration of TRIZ } \\
\text { and mathematics; expanded research beyond Patterns of Evolution to } \\
\text { the development of over } 125 \text { Evolutionary Sequences describing how } \\
\text { systems have evolved throughout history in great detail. }\end{array}$ \\
\hline $\begin{array}{l}\text { Primary user base: engineers, scientists, } \\
\text { quality professionals. }\end{array}$ & $\begin{array}{l}\text { Primary user base: business leaders, managers, engineers, scientists, } \\
\text { quality professionals with expansion into education. }\end{array}$ \\
\hline $\begin{array}{l}\text { Leverages historic paradigm by targeting } \\
\text { the development of individual skills. }\end{array}$ & Focuses on both individuals and teams with an emphasis on the latter. \\
\hline $\begin{array}{l}\text { Collection of methods, tools and } \\
\text { techniques that change the way people } \\
\text { think. }\end{array}$ & $\begin{array}{l}\text { Collection of methods, tools and techniques designed to change the } \\
\text { way people think; facilitation methods designed to involve teams in } \\
\text { the problem solving process and develop ownership among those } \\
\text { involved in solving problems. }\end{array}$ \\
\hline $\begin{array}{l}\text { Contains and promotes antiquated } \\
\text { methods, tools and techniques such as } \\
\text { contradiction table, su-field modeling, } \\
\text { ARIZ - all of which where vital to the } \\
\text { foundational development of theory but } \\
\text { are not viable for practical application. }\end{array}$ & $\begin{array}{l}\text { Replaces contradiction table with an analytical process that can be } \\
\text { applied to any defined contradiction; leverages the foundational } \\
\text { thinking of su-field but not as a solving tool, utilizes a simplified, } \\
\text { improved model to replace the complexity of ARIZ. Expands beyond } \\
\text { the limitations of the Patterns of Evolution to include Evolutionary } \\
\text { Sequences. }\end{array}$ \\
\hline $\begin{array}{l}\text { Educationally focused on engineering } \\
\text { and science. }\end{array}$ & $\begin{array}{l}\text { Educational expansion includes linkages to entrepreneurship, science, } \\
\text { mathematics, history, literature, communications, etc. }\end{array}$ \\
\hline
\end{tabular}

- Results: Within 20 hours the team had identified the missing characteristics, modified formulas and improved simulations to the satisfaction of the leading experts; improved simulations lead to the invention of a new technology to protect electronic systems from instantaneous high energy releases.

○ Link "evolutionary patterns" to history

- Opportunity: Helping students understand that systems evolve based on objective patterns and not randomly helps develop understanding of how and why our world has evolved. 
- Link "ideality" to the creation of the design of measurement systems

- Situation: Team of engineers was faced with the need to reduce the time required to test connectors in a caustic environment while inducing temperature variations, vibration, humidity changes and other characteristics. The plan included the use of 18 designed experiments of 200 hours each in a HALT (highly accelerated life test) costing roughly $\$ 500 \mathrm{k}$. The time require (3600 hours) combined with the risk of damage to the chamber were both serious concerns. The team had been trying to figure out how to reduce the time required to conduct the tests and reduce the risk to the chamber for $2 \frac{1}{2}$ months without making progress.

- Solution: The problem was redefined in terms of "ideality", i.e., the function is performed without the existence of the system that carries the problem. The system carrying the problems was the HALT chamber; it determined the need for sequentially processing of the tests and was at risk of being damaged.

- Results: Within 15 minutes the team redefined how the test would be run without the use of the chamber by creating small, low cost cylindrical chambers matched to the size of the connectors. Each chamber had an independently controlled environment, provided by a small peristaltic pump, a transducer for vibration and heater bands for temperature control. The total time required to run the tests was immediately reduced to 200 hours and the risk to the HALT chamber was eliminated.

○ Link to history and communications

- Opportunity: Study the history of subjects based on evolution \& innovation principles, for example:

- In the beginning humans communicated in grunts and groans (initial state: minimal structure).

- Eventually, verbal language evolved to allow for the collection and sharing of information and the development of relationships (principle: increased structure).

- Next was the creation of alphabets and written language which provided for the development of business, society, government and laws plus the development of stable transferrable information (principle: increased structure and function transfer from human to a technological system).

- Then came books and the ability to distribute and exchange information to large groups of people (principle: increased structure and increased transportability).

- This was followed by the mass production of paper and printing technologies resulting in periodicals and newspapers (principles: the use of copies, decreased human involvement, increased dynamics and increased controllability).

- But we were not done yet - print transitioned to electronic communications in the form of telegraph (principle: transition to the micro-level).

- Eventually to computerize information (principle: increased complexity, function transfer from human to a technological system and increased structure). 
The above is only a sampling of some of the principles that were applied as man / woman innovated the way communications occurs.

There are many opportunities to link to all areas of education that will be discovered by the teachers and developers of educational materials as they become more aware of the underlying principles of TRIZ and Structured Innovation.

\section{Conclusions}

Both of the authors believe that courses in Structured Innovation have much to offer the learner. In a few weeks our students were able to learn taught a foundational "body of knowledge" that changed the way they think. The course resulted in different approach to solving problems. The application of the knowledge enhanced each student's ability to tackled difficult problems utilizing the methods, tools and resources of the Structured Innovation process. The feedback and results of the team effort was evidence that the lessons learned made a difference.

The course was offered to juniors and seniors as a one credit hour elective and was available within the College of Engineering. Based on this, we felt the course should have been mandatory and included in a product design component prior to the assignment of senior projects. It is also important to include a laboratory component into the course. Students must have time to apply the knowledge and link theory and practice. This experiential learning component is a key to the successful application of theory. Moving beyond the basics, the opportunity is to integrate elements of Structured Innovation processes, methods, tools and techniques into other courses and to expand on this foundational "body of knowledge" to prepare students for more advanced courses.

Structured Innovation can be used in everyday life. Learning the methods and tools add value to the student's ability to compete and differentiate them in today workplace. Our educational system must not only provide our students with basic tools to innovate but also prepare them for more advanced applications. Without these capabilities, methods and tools, it will become increasingly difficult to compete on a global basis.

\section{References}

1. Dana W. Clarke, Sr., TRIZ: Through the Eyes of an American TRIZ Specialist, Applied Innovation Alliance, 2002.

2. Dana W. Clarke, Sr., Structured Innovation: Foundational Elements, Applied Innovation Alliance, 2002.

3. GDLS' Landmarks July 2007.

4. Genrich Altshuller, Innovation Algorithm, 1973.

5. Clayton Christensen, Innovator's Dilemma, 1997.

6. Gifford Pinchot III, Intrapreneuring, 1985. 